\title{
The Relevant Market for Production and Wholesale of Electricity in the Nordic Countries: An Econometric Study
}

\author{
Mikael Juselius \\ University of Helsinki and HECER \\ and \\ Rune Stenbacka \\ Swedish School of Economics (Helsinki) and HECER
}

Discussion Paper No. 222

May 2008

ISSN 1795-0562

HECER - Helsinki Center of Economic Research, P.O. Box 17 (Arkadiankatu 7), FI-00014 University of Helsinki, FINLAND, Tel +358-9-191-28780, Fax +358-9-191-28781,

E-mail info-hecer@helsinki.fi, Internet www.hecer.fi 


\title{
The Relevant Market for Production and Wholesale of Electricity in the Nordic Countries: An Econometric Study
}

\begin{abstract}
We apply cointegration analysis to hourly Nord Pool prices covering the period 2001-2007 in order to empirically characterize the geographical dimension of the relevant market for production and wholesale of electricity. We reach the following econometric conclusions: (i) Finland, Sweden and Norway 3 unambiguously belong to the same relevant market, (ii) Denmark 2 belongs to this same market except for the subsample 2004-2007, (iii) Norway 1 and Denmark 1 define separate markets on their own. We also find that the stochastic trends in Nord Pool prices originate in countries abundant in capacity for generating hydro power.
\end{abstract}

JEL Classification: L94, L40, C32

Keywords: Definition of Relevant Market, Geographical Relevant Market, Nord Pool, International Transmission Capacity, Price Areas, Cointegration

Mikael Juselius

Department of Economics

University of Helsinki

P.O. Box 17 (Arkadiankatu 7)

00014 University of Helsinki

FINLAND

e-mail: Mikael.Juselius@helsinki.fi
Rune Stenbacka

Department of Economics

Swedish School of Economics

P.O. Box 479

00101 Helsinki

FINLAND

e-mail: Rune.Stenbacka@hanken.fi 


\section{Introduction}

Theoretical analysis in economics typically refers to the market as if its definition were self-evident. However, in antitrust cases much effort is invested in order to present a precise definition of the relevant market with respect to both product dimensions and geographic dimensions. The implementation of competition law always requires that the relevant market is defined in a systematic and careful way. In this study we will present an econometrically founded analysis of how to define the relevant market with respect to production and wholesale of electricity in the Nordic countries with an emphasis on the geographical dimension. We will adopt a Finnish perspective on the geographical extension of the relevant market. Is the relevant market national (Finnish) or does it incorporate additional price areas in Nord Pool? In particular, is the relevant market perhaps so extensive so as to capture all the price areas, Finland, Sweden, Norway 1, Norway 2, Norway 3, Denmark 1 and Denmark 2, in Nord Pool? ${ }^{1}$

In general, the standard approach in European competition law for how to define the relevant market is to apply the SSNIP-test ("Small but Significant Non-transitory Increase in Price"). The SSNIP-test essentially asks whether a customer would switch to a competitor if confronted with a small but significant non-transitory increase in price. Thereby the crucial question when applying the SSNIP-test to Finland is to essentially ask the following: Could a hypothetical firm with sufficiently strong market power in Finland profitably impose a non-transitory $5-10 \%$ price increase without being challenged by competition from non-Finnish producers, for example, from Nord Pool producers located outside of Finland? In other words, would a buyer switch to a non-Finnish supplier if a hypothetical Finnish monopolist would impose a non-transitory 5-10\% price increase?

We initially restrict our analysis to the issue of whether Finland and Sweden are part of the same relevant market for production and wholesale of electricity. For the national Finnish market to define its own relevant market the SSNIP-test requires a certain permanency or persistence if there is a Finnish price increase. Is it likely that failures of imports from Sweden to discipline such a price increase exhibit such a persistency and predictability so as to qualify for the criterion of a non-transitory price increase in the legal sense of the SSNIP-test? Of course, it is more demanding than this to establish that Finland constitutes a separate national market. If we were unable to establish that Finland and Sweden belong to the same relevant

\footnotetext{
${ }^{1}$ When presenting the data in subsection 4.1 we characterize these price areas more precisely.
} 
market we would have to demonstrate that imports from no other countries belonging to Nord Pool, from Russia or from Estonia would not substitute for the Swedish imports when a bottleneck for imports from Sweden is realized. ${ }^{2}$ Such a substitution would seem likely unless it can be shown that bottlenecks for the import from other Nordic countries, Russia and Estonia coincide with bottlenecks for the imports from Sweden. Subsequently we extend our analysis to the whole Nord Pool area for the time period 2001-2007.

From a strictly theoretical point of view the relevant geographic market should be determined on the basis of estimates of cross elasticities of demand across different price areas as well as estimates on marginal costs. However, such an approach typically imposes too severe data restrictions for the purpose of antitrust implementation. For that reason the literature has developed a number of empirical approaches to exploit time series properties of area-specific prices as the basis for the definition of the geographical dimension of the relevant market. Prominent examples in this respect include Horowitz (1981), Slade (1986), Spiller and Huang (1986) and Uri and Rifkin (1985). These empirical approaches capture the basic idea that arbitrage will prevent prices in different price areas from moving independently of each other if these price areas belong to the same relevant market (see, Stigler and Sherwin (1985)).

Walls (1994) and Forni (2004) have econometrically interpreted the market definition as implying cointegration between prices within the same market. In this paper, we apply a similar cointegration approach to characterizing market delineation within a more general system framework. This is particularly valuable when there are more than two price areas, because potentially conflicting results from mutually pairwise tests can be avoided. Furthermore, our approach allows us to obtain a representation of the common stochastic trends, which may be informative for understanding the mechanisms underlying common price movements (for example, access to hydro power). In addition, we test weak (long-run) exogeneity in order to explore whether the common stochastic trend originate in one particular area relative to the others within the same relevant market.

The promotion of competition and efficiency in the European electricity markets has been a strong policy priority for the European Commission. Operational criteria for how to define a relevant market in a geographical sense serve as a precondition for economic assessments of the electricity industry no matter whether a merger case or a case focusing on potential abuse of market dominance (Article 82) is evaluated. Thus, the operational criteria

\footnotetext{
${ }^{2}$ The design of Nord Pool implies that prices across areas are equalized if there are no restrictions (bottlenecks) in transmission capacity between areas.
} 
for how to geographically define the relevant market servers as a crucial instrument of competition policy (see, for example, Vandezande et al. (2006)). In its recent sector inquiry on the gas and electricity industries the European Commission (2007) presents a detailed discussion of the market for production and wholesale of electricity in the Nordic countries. This sector inquiry pays attention to the following factors as central when evaluating whether Finland and Sweden form an integrated market. (i) The correlation between the prices in Finland and Sweden. (ii) The similarity of Finnish and Swedish prices of the contracts for differences (CfD's) in the forward markets. (iii) Nord Pool as an integrated market design for the Finnish and Swedish electricity market. Relatedly, in the case Sydkraft/Graninge ${ }^{3}$ the European Commission's market analysis reaches the following conclusion regarding the definition of the relevant geographic market: "... it is clear that Sweden has only constituted a separate geographic area during an insignificant period of time in each of the last years. At the same time the price correlation between Sweden and Finland and Sweden and Denmark seems to imply that the generation / wholesale market is likely to be larger than Sweden" (see, $\S$ 27 of the decision).

The geographical dimension of the relevant market for production and wholesale of electricity has also been subject to decisions on the national level in the Nordic countries. In a decision concerning Sweden and dated 7 May 2007 the Swedish Competition Authority concludes that the relevant market for production and wholesale of electricity is Nordic or at least larger than the national market. Contrary to this view, in its evaluation in year 2006 of the recent acquisition by Fortum Power and Heat Oy of E.ON Finland the Finnish Competition Authority seemed to suggested an intertemporal separation according to which the relevant market would be the national Finnish market under the phase when there are bottlenecks for the transmission of electricity between Finland and Sweden, whereas the relevant market would include both countries when such bottlenecks are not binding. However, the definition of the relevant market suggested by the Finnish Competition Authority was rejected by the Finnish Market Court in its ruling dated 14 March 2008. According to the Market Court, the relevant geographical market area consists of at least Finland and Sweden.

This paper is organized as follows. In Section 2 we present our approach for how to econometrically define the relevant market. The statistical model is presented in Section 3. In Section 4 we apply cointegration analysis to hourly Nord Pool prices during the period 2001-2007 in order to empirically characterize the geographical dimension of the relevant market for production

\footnotetext{
${ }^{3}$ Case No COMP/M.3268 (30.10.2003).
} 
and wholesale of electricity. In Section 5 we evaluate the policy option of an intertemporal separation in the definition of the relevant market. Section 6 concludes.

\section{An Econometric Approach to Delineation of Markets}

Within a market operating under conditions with competition the demand faced by one firm is dependent on the prices set by the other firms. This interconnectivity of demands implies that exogenous shocks, even if they are firm-specific, trigger price reactions among all firms in the market. In other words, prices in the same market internalize the same set of shocks and cannot, therefore, persistently deviate from (some) market equilibrium. Such deviations can survive only as a temporary phenomenon.

This property implies a high degree of correlation between the prices in areas belonging to the same relevant market. This high degree of correlation can statistically be exploited to empirically characterize the relevant market from observed price data. However, prices in separate markets can also display a high degree of correlation due to, for instance, common exogenous factors. ${ }^{4}$ Hence, a high degree of correlation between prices alone is not in general sufficient to delineate markets unless such common factors have been accounted for. In addition, there should be no significant deterministic deviations between prices. ${ }^{5}$

In a non-stationary price environment, the condition placed on the evolvement of prices belonging to the same market is more stringent: The prices must share the same stochastic trends in the same relative proportions, i.e. they must be cointegrated. If they are not, arbitrarily large deviations between the prices are possible in the long-run, a feature which is not consistent with equilibrium under conditions with interconnected demands. By contrast, even in the unlikely case where prices in separate markets share the same stochastic trends, there is no reason why the composition of these trends should be proportional. Hence, prices in separate markets will in general not be cointegrated. Thus, in the non-stationary case cointegration between prices serves as a substitute for taking exogenous common factors

\footnotetext{
${ }^{4}$ For example, consider the price of flight tickets and taxi fares in the face of an oil price shock.

${ }^{5}$ There is no objective benchmark as to what constitutes a significant deterministic deviation with respect to market delineation. For example, in some cases a significant difference in the mean of the prices may be sufficient for them to belong to separate markets (e.g. homogeneous goods markets) while this may not be sufficient in other cases.
} 
into account.

Specifically, let $p_{i, t}$ be the price in area $i$ and $p_{j, t}$ the price in area $j$. If these areas define the same market in the sense above and prices are nonstationary we can represent the prices according to

$$
\begin{aligned}
& p_{i, t}=c_{i} \sum_{h=1}^{t} \varepsilon_{h}+c_{i}^{*}(L) \varepsilon_{i, t} \\
& p_{j, t}=c_{j} \sum_{h=1}^{t} \varepsilon_{h}+c_{j}^{*}(L) \varepsilon_{j, t}
\end{aligned}
$$

where $\sum_{h=1}^{t} \varepsilon_{h}$ is the common stochastic trend, ${ }^{6} \varepsilon_{i, t}$ and $\varepsilon_{j, t}$ are area-specific shocks, the parameters $c_{i}$ and $c_{j}$ are the loadings to this stochastic trend, and the roots of the polynomials $c_{i}^{*}(z)$ and $c_{j}^{*}(z)$ are outside the unit circle. Thus, the prices must be cointegrated with cointegration vector $\beta=\left(1,-c_{i} / c_{j}\right)^{\prime}$. The requirement of cointegration does not, as such, imply that $c_{i}=c_{j}$. For example, if the products are not perfect substitutes the loadings may very well differ. However, if the products are perfect substitutes the price areas define the same market if $c_{i}=c_{j}$ and hence the cointegration vector $\beta=(1,-1)^{\prime}$. Walls (1994) applies precisely this approach when characterizing the relevant geographical market for the U.S. natural gas industry. ${ }^{7}$ For this homogeneous market he tests the more stringent pairwise condition that $c_{i}=c_{j}$ to all areas in his sample. Importantly, he also proposes a less stringent market definition by testing $\left|\left(c_{i} / c_{j}\right)-1\right| \leq \delta$, for some $\delta \geq 0$. In this paper we advocate the general view that cointegrated price series are a sufficient and necessary condition for two areas to define the same market. The acceptable deviation from unity in the proportion of the loadings is industry-specific and determined by the degree of substitutability between the products in terms of both the product characteristics and geographic barriers (for example, transportation costs).

Thus, in the non-stationary case, the issue of market delineation for homogeneous goods can econometrically be decomposed into three separate questions.

(i) Can we reject the hypothesis of cointegration between the prices, i.e. is there evidence that the prices have deviated from equilibrium in a long-run perspective?

\footnotetext{
${ }^{6}$ The common stochastic trend can be interpreted as an aggregate of several structural stochastic trends that enter the prices proportionally, with the relative proportion $c_{i} / c_{j}$.

${ }^{7}$ Related conditions for both product and geographical market delineation are tested in Horowitz (1981) and Forni (2004).
} 
(ii) Can we reject the hypothesis of long-run homogeneity in cointegrated prices?

(iii) Are there significant deterministic differences between the prices?

If the answer to any of these questions is affirmative we must reject the hypothesis that the firms belong to the same relevant market. If, on the other hand, the answer to all questions is negative, we should conclude that the firms belong to the same relevant market.

On a fundamental level competition policy, like microeconomic policy more generally, targets structural market imperfections with long-run effects. Consistent with this general perspective the SSNIP-test specifies that the relevant market should be defined based on the ability of a hypothetical firm with sufficiently strong market power to impose a price increase with a sufficient degree of permanency or persistence. The criterion of permanency or persistence should reasonably be determined in light of the prevailing mode of competition so as to match industry-specific factors like the required time to observe rivals' prices, to implement price responses, and possibly also to conduct capacity adjustments. This means that the relevant market cannot be too narrowly defined in an intertemporal sense so as to capture individual hours, minutes or seconds. Under all circumstances the time required for unconstrained competition to discipline a price set above a level consistent with competition defines a lower bound for the horizon, shorter than which an intertemporal definition of the relevant market would not be meaningful. Hence, the empirical condition that prices within a relevant market should be cointegrated and homogeneous is consistent with the implications of belonging to the same market according to the SSNIP-test.

We can summarize our econometric procedure, whereby the relevant market is defined, in a logical sequence of steps. In the first step we determine whether the price series are stationary or not since the statistical inference is crucially dependent on this property. If the prices are stationary and significantly correlated, we must control for possible common factors and investigate their relative deterministic differences in order to decide if the areas belong to the same market. On the other hand, if prices are non-stationary, mean reversion around their combined deterministic components can only occur if they are cointegrated. ${ }^{8}$ Thus, only if the prices are cointegrated, homogeneous and do not differ significantly with respect to their deterministic differences can we can conclude the firms belong to the same relevant market. Figure 1 summarizes this procedure. We apply this procedure to

\footnotetext{
${ }^{8}$ In the intermediate case where one price is stationary while the other is not, there cannot by definition be any mean reversion between the series. Thus, such a result would
} 
Flow chart of the econometric procedure

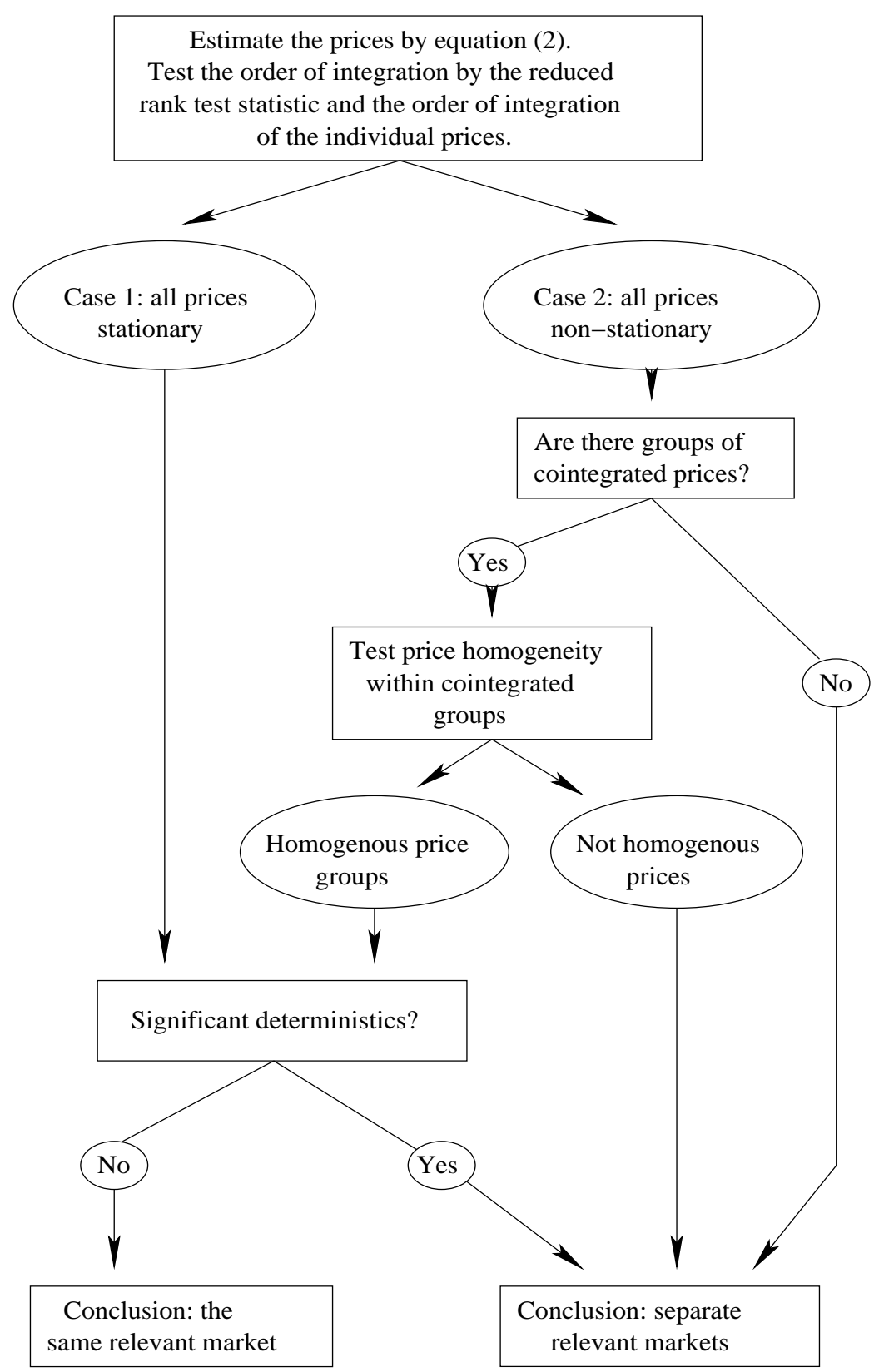

Figure 1: Flow chart of the econometric procedure. 
characterize the relevant market for production and wholesale of electricity in the Nordic countries in Section 4.

\section{The Statistical Model}

The implementation of the econometric approach outlined in the previous section requires a statistical framework that can be used to analyze the integration and cointegration properties of a vector of prices. A natural choice is the vector auto-regressive (VAR) model in its error correcting form.

The $p$-dimensional VAR model with $k$ lags is given by

$$
X_{t}=\sum_{i=1}^{k} A_{i} X_{t-k}+\Psi D_{t}+\varepsilon_{t}
$$

where $X_{t}$ is a $p$-dimensional time series vector, $A_{i}(i=1, \ldots, k)$ and $\Psi$ are parameter matrices, $D_{t}$ is a $p \times f$ matrix that collects the deterministic components, and $\varepsilon_{t} \sim N_{p}(0, \Sigma)$. In our application $X_{t}$ will be a vector of prices from areas that potentially belong to the same market. If $X_{t} \sim$ $I(1)$ (integrated of the first order) it is convenient to transform (1) into its corresponding error correction form

$$
\Delta X_{t}=\sum_{i=1}^{k-1} \Gamma_{i} \Delta X_{t-i}+\Pi X_{t-1}+\Psi D_{t}+\varepsilon_{t}
$$

where parameter matrices $\Gamma_{i}$ and $\Pi$ are functions of the $A_{i}$ matrices. The properties of this model are extensively investigated in Johansen (1995).

Cointegration can be tested as a reduced rank hypothesis on the $\Pi$ matrix. If the rank, $r$, of $\Pi$ is equal to $p$ we can conclude that $X_{t}$ is stationary, i.e. $X_{t} \sim I(0)$. If $0<r<p$, then $X_{t} \sim I(1)$ is cointegrated with $r$ cointegration vectors and $p-r$ common stochastic trends. In this case, $\Pi=\alpha \beta^{\prime}$, where $\alpha$ and $\beta$ are two $(p \times r)$ matrices of full column rank. The cointegration space is spanned by $\beta^{\prime}$. If $r=0$ then $X_{t} \sim I(1)$ and the process is not cointegrated.

An important special case of (2) is obtained when $0<r<p$ and a deterministic linear trend is restricted to the cointegration space. The reason for restricting the linear trend is that (2) implies quadratic trends in $X_{t}$ otherwise. If the trend is restricted, $\Pi X_{t-1}$ in (2) can be written as $\alpha \tilde{\beta}^{\prime} \tilde{X}_{t-1}$, where $\tilde{\beta}=\left(\beta^{\prime}, \kappa\right)^{\prime}, \kappa$ is a $r$-dimensional vector, and $\tilde{X}_{t-1}=\left(X_{t-1}^{\prime}, t\right)^{\prime}$.

The test for the reduced rank of $\Pi$, known as the trace test, was developed by Johansen (1991). The null hypothesis of the trace test is that the rank of

indicate that the price areas do not belong to the same relevant market. 
$\Pi$ is less or equal to $r$. Hence, the natural testing sequence from a statistical point of view is to start by testing $r=0$ and then successively increasing the rank by one until the first non-rejection. The likelihood ratio test statistic (trace test) of the hypothesis that the cointegration rank is $r$ or less is given by

$$
-2 \log Q(r)=-T \sum_{i=r+1}^{p} \log \left(1-\lambda_{i}\right)
$$

where $\lambda_{i}$ are the eigenvalues of a reduced rank regression and $T$ is the sample size. Thus, the test will reject if the eigenvalues corresponding to the $p-r$ common stochastic trends are statistically far from unity.

Given $\Pi=\alpha \beta^{\prime}$, general linear hypotheses on $\beta$ can be tested in the form

$$
\mathcal{H}_{\beta}: \beta=\left(H_{1} \varphi_{1}, \ldots, H_{r} \varphi_{r}\right)
$$

where $H_{i}\left(p \times\left(p-m_{i}\right)\right)$ imposes $m_{i}$ restrictions on $\beta_{i}$, and $\varphi_{i}\left(\left(p-m_{i}\right) \times 1\right)$ consists of $p-m_{i}$ freely varying parameters. The likelihood ratio test of the hypotheses is asymptotically $\chi^{2}$. Stationarity of an individual variable in $X_{t}$ can be tested by formulating $H_{i}$ in such a way that one of the $\beta$-vectors is a unit vector.

The $\alpha$-vectors can also be restricted in a similar way. Of special interest is the case where one or several rows in $\alpha$ consist of zeros. A variable with a zero row in $\alpha$ is said to be weakly exogenous. A weakly exogenous variable generates a common stochastic trend and is not affected by the other stochastic trends in the system. In this sense, a weakly exogenous variable can be viewed as a forcing variable in the long-run.

In our application it will sometimes be more convenient to obtain a representation of the $p-r$ common stochastic trends rather than the stationary relations $\beta$ when $p>2$. The reason is that the common trends representation contain the same statistical information as $\alpha$ and $\beta$, but relieves us from testing $\left(\begin{array}{l}p \\ 2\end{array}\right)$ cointegrating combinations between the prices. Instead, the cointegrating combinations can be directly read from the common trends representation. ${ }^{9}$ The inverse of (2), provided by the Granger-Johansen representation theorem is

$$
X_{t}=C \sum_{i=0}^{t-1}\left(\varepsilon_{t}+\Psi D_{t}\right)+C(L)\left(\varepsilon_{t}+\Psi D_{t}\right)+X_{0}
$$

where $C=\beta_{\perp}\left(\alpha_{\perp}^{\prime}\left(I-\sum_{i=1}^{k-1} \Gamma_{i}\right) \beta_{\perp}\right)^{-1} \alpha_{\perp}^{\prime}, C(L)$ is a stationary matrix lag-polynomial with zeros outside the unit circle, $X_{0}$ summarizes the initial

\footnotetext{
${ }^{9}$ However, cointegration tests can be utilized when the common trends representation yields ambiguous results.
} 
condition, and $\alpha_{\perp}$ and $\beta_{\perp}$ denotes the orthogonal complements to $\alpha$ and $\beta$. The is the common trends representation of $X_{t}$. The matrix $\alpha_{\perp}^{\prime}$ exhibits the common stochastic trends, whereas $\beta_{\perp}\left(\alpha_{\perp}^{\prime}\left(I-\sum_{i=1}^{k-1} \Gamma_{i}\right) \beta_{\perp}\right)^{-1}$ provides the loadings of the common stochastic trends into each element of $X_{t}$.

\section{Application to Nord Pool price data}

In this section we apply the econometric approach to price data from the Nordic market for production and wholesale of electricity, Nord Pool. Within Nord Pool wholesale prices of electricity are perfectly equalized among firms within a given price area. Therefore, rather than considering the prices of individual firms we investigate the relevant market delineation among Nordic price areas instead. We begin by investigating if the price areas Finland and Sweden belong to the same relevant market. We then extend the analysis to cover all price areas of Nord Pool.

\subsection{Data, Frequency and Aggregation}

The data consists of hourly observations on prices from the following Nord Pool price areas: Finland, Sweden, Norway 1, Norway 2, Norway 3, Denmark 1, and Denmark 2. In the terminology used by Nord Pool, Norway 1 refers to South-Norway (the Oslo area), Norway 2 to mid-Norway (the Trondheim area), Norway 3 to North-Norway (the Tromsö area), Denmark 1 to East-Denmark (the Copenhagen area) and Denmark 2 to West-Denmark (the Odense-area). Due to the almost complete correlation between Norway 2 and Norway 3, we only consider Norway 3 in the analysis in order to avoid severe multicollinearity problems. ${ }^{10}$ The price observations cover the period 2001:01:01:00-2007:12:31:23, which means that the sample consists of 61337 observations in total. Figures 2 and 3 depict the area-specific prices (aggregated to a weekly frequency to facilitate the exposure). Table 1 presents descriptive evidence on price convergence between Finnish and Swedish prices during the period 2001-2007. The correlation coefficient between Finnish and Swedish prices exceeds 0.96 for all years except 2005 and 2006. The mean of the price difference in the original hourly data, $P_{t}^{F I N}-P_{t}^{S W E}$, is -0.140 and the corresponding t-value is 5.71. Furthermore, the median of the price difference is zero.

The large number of observations causes two particular econometric problems, one computational and the other statistical in nature. The first problem

\footnotetext{
${ }^{10}$ Moreover, price data on Norway 2 is only available from 2003:07:23:00 onwards.
} 

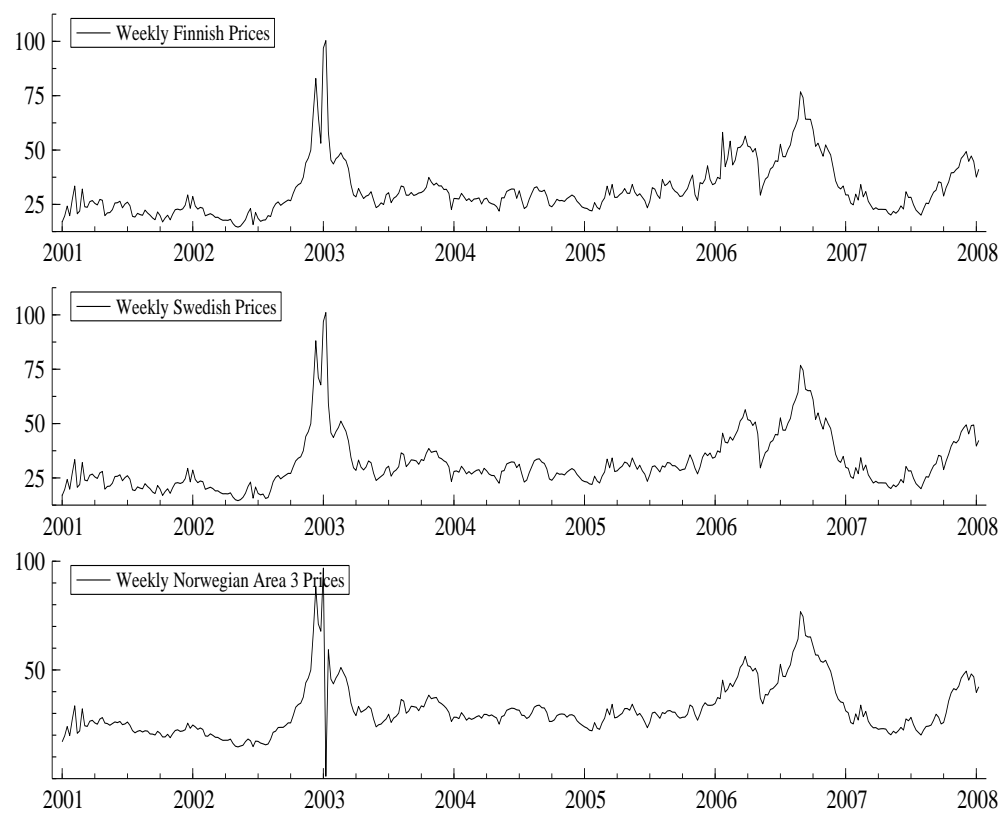

Figure 2: Weekly price aggregates for Nord Pool price areas Finland, Sweden, and Norway 3.

\begin{tabular}{cccccccc}
\hline \multicolumn{6}{c}{ Finnish and Swedish Prices: Correlation and Price Differences } \\
\hline \hline \multirow{2}{*}{$\operatorname{corr}\left(P_{t}^{F I N}, P_{t}^{S W E}\right)$} & 2001 & 2002 & 2003 & 2004 & $\left.2005^{*}\right)$ & 2006 & 2007 \\
$P_{t}^{F I N}$ & 22.84 & 0.967 & 0.984 & 0.970 & 0.783 & 0.852 & 0.988 \\
$P_{t}^{S W E}$ & 22.86 & 27.61 & 36.49 & 27.68 & 30.53 & 48.57 & 30.01 \\
$P_{t}^{F I N}-P_{t}^{S W E}$ & -0.02 & -0.34 & -1.18 & -0.40 & 0.77 & 0.45 & -0.25 \\
\hline
\end{tabular}

Table 1: Finnish vs Swedish area prices (in Euro). *) A two hour price spike at 8.12.2005 which is fully due to Svenska Kraftnät's operation is removed from the data. 

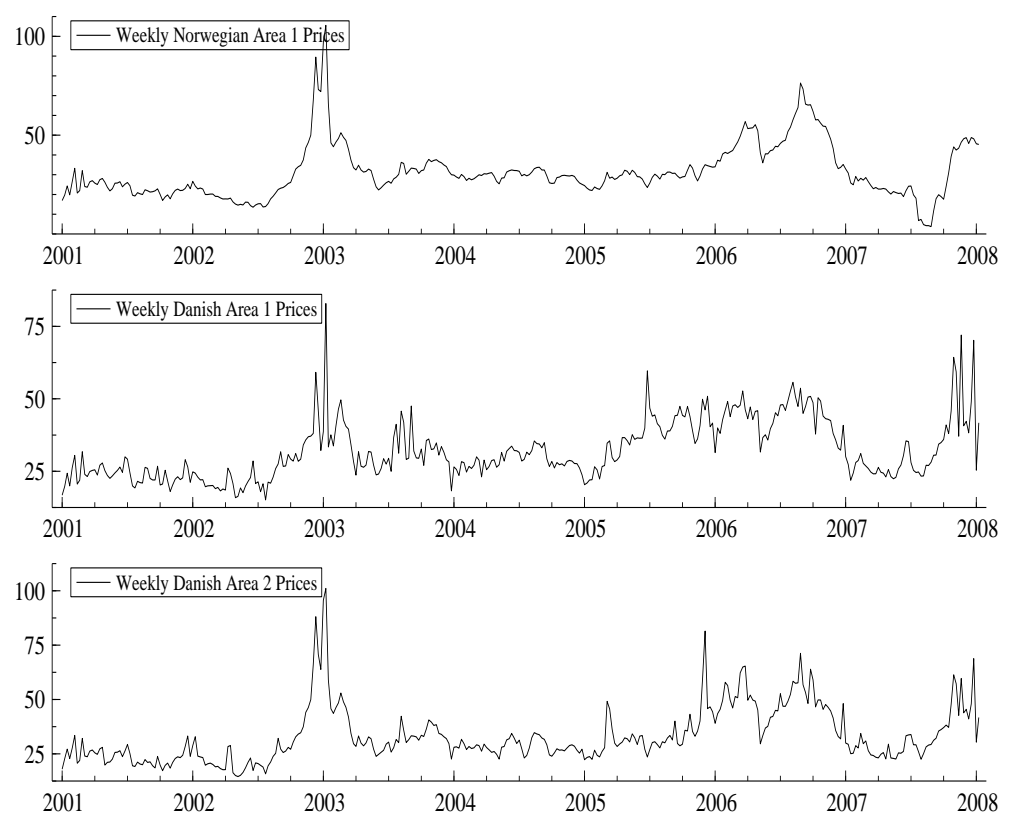

Figure 3: Weekly price aggregates for Nord Pool price areas Norway 1, Denmark 1 and Denmark 2.

arises as the computational power of modern PCs is simply not sufficient to calculate the trace test statistic for a well-specified model of the hourly data. The second problem is that the large number of observations associated with the hourly frequency increases the power of virtually all statistical tests (see for example Otero and Smith (2000)). Of particular concern in this context is that the increase in power associated with the hourly frequency would tend to create a bias towards the conclusion that the price areas belong to the same relevant market. In this study we are particularly concerned with errors of type I, i.e. we want to avoid defining the market too broadly. Furthermore, with hourly observations it is difficult to account for all exogenous events that cause symmetric additive outliers in the price series. Such outliers can cause an additional bias towards cointegration or even stationarity (see Bohn Nielsen (2004) and Franses and Haldrup (1994), among others).

From a statistical point of view temporal aggregation reduces the power of the tests and makes the problem with outliers manageable. The reason is that averaging over periods preserves the integration and cointegration properties of the data while reducing the total sample size $T$ (see Marcellino, 1999). Thus, we will mainly operate with daily aggregates of the price data in this paper. However, we conduct robustness checks with both weekly and 

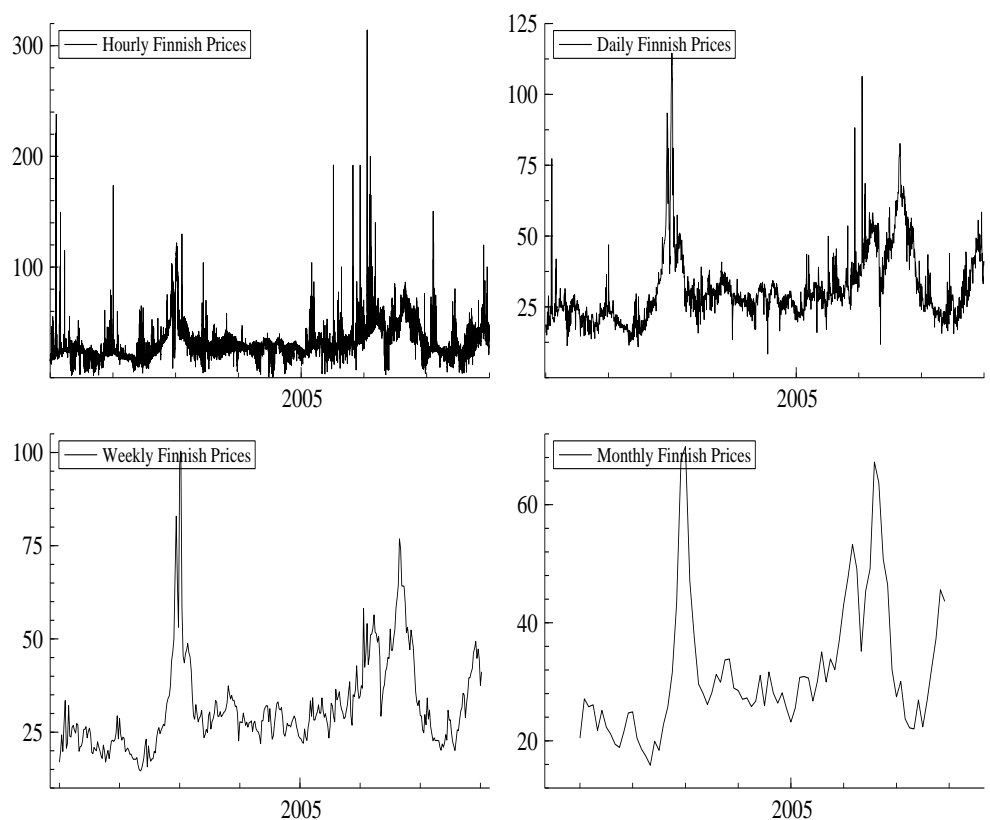

Figure 4: Hourly, Daily, Weekly, and Monthly aggregates of Finnish prices.

monthly frequencies. Moreover, to the extent that results are obtainable with hourly observations these essentially coincide with the results based on daily observations.

The number of observations for each price area at the daily frequency is 2556. Figure 4 shows Finnish area prices at different frequencies of aggregation (hourly, daily, weekly and monthly). While the aggregation, of course, reduces the short-term volatility, the long-run stochastic trend is invariant to aggregation, as Figure 4 graphically supports.

\subsection{Tests with Finnish and Swedish Prices}

We begin by applying our procedure to Finnish and Swedish prices. Figure 5 presents a graphical exposition of the daily electricity prices (logarithms) in Finland and Sweden for the period 2001-2007 as well as the homogeneous price difference $p_{t}^{F I N}-p_{t}^{S W E}$. This figure shows a very high correlation between the prices in Finland and Sweden. In fact, the correlation is so high that for most of the time it is optically impossible to distinguish the Finnish price from the Swedish price.

The (logs of) Finnish and Swedish prices, $p_{t}^{F I N}$ and $p_{t}^{S W E}$, are modeled by (2), where a trend is restricted to the cointegration space. We add 6 


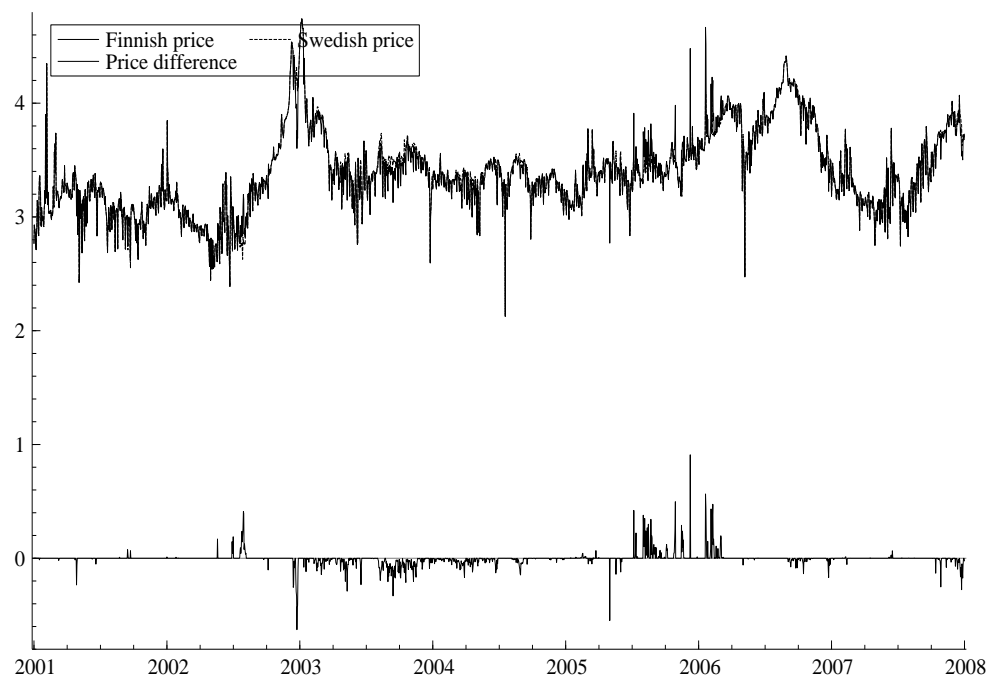

Figure 5: The homogeneous price difference between Finland and Sweden, and the price levels.

centered seasonal dummies to account for daily seasonal variation within the week and 11 centered seasonal dummies to account for monthly seasonal variation within the year.

Initial modeling of the data, indicated that 32 additional dummy variables were needed to account for extreme exogenous events that affect both Finnish and Swedish prices symmetrically. These dummies do not reflect any significant price deviations between Finland and Sweden, but rather symmetric exogenous shocks that cannot be accounted for by any reasonable choice of lag length. Ignoring these outliers would lead to $(i)$ misspecification and unreasonably many lags in the auto-regression, and (ii) distortions of the trace test statistic which cause over-rejection of the null of any given rank $r$, i.e. they essentially bias the results towards stationarity and would thereby introduce a tendency of excessive acceptance of the hypothesis that Finland and Sweden belong to the same relevant market. The initial analysis also revealed a number of idiosyncratic shocks to either price series. These were not blocked out by dummy variables.

The choice of lag-length, $k$, was based on the Schwarz and Hannan-Quinn information criteria which indicated that between 4 and 7 lags were needed in order to account for the variation in the data. We chose a lag structure with 7 days to capture potential systematic patterns related to the time of the week. However, any lag $k$ above 4 days yields virtually identical results as those reported below. It should also be noted that the seasonal dum- 


\begin{tabular}{|c|c|c|c|c|c|c|c|c|}
\hline \multicolumn{9}{|c|}{ Reduced rank hypothesis, $X_{t}=\left(p_{t}^{F I N}, p_{t}^{S W E}\right)^{\prime}$} \\
\hline \multirow[t]{2}{*}{ Sample } & \multicolumn{4}{|c|}{$r=0$} & \multicolumn{4}{|c|}{$r=1$} \\
\hline & $\lambda_{i}$ & $\operatorname{Tr}$ & $\operatorname{Tr} 95$ & p-val & $\lambda_{i}$ & $\operatorname{Tr}$ & $\operatorname{Tr} 95$ & p-val \\
\hline Full sample, 01-07 & 0.055 & 153.04 & 25.73 & 0.000 & 0.003 & 9.34 & 12.45 & 0.164 \\
\hline Half sample, 04-07 & 0.056 & 88.74 & 25.73 & 0.000 & 0.003 & 4.67 & 12.45 & 0.649 \\
\hline Year 01 & 0.098 & 56.17 & 25.73 & 0.000 & 0.052 & 19.09 & 12.45 & 0.003 \\
\hline Year 02 & 0.081 & 38.97 & 25.73 & 0.000 & 0.024 & 8.86 & 12.45 & 0.194 \\
\hline Year 03 & 0.097 & 58.92 & 25.73 & 0.000 & 0.061 & 22.49 & 12.45 & 0.001 \\
\hline Year 04 & 0.069 & 33.93 & 25.73 & 0.003 & 0.023 & 8.31 & 12.45 & 0.234 \\
\hline Year 05 & 0.097 & 50.48 & 25.73 & 0.000 & 0.038 & 13.97 & 12.45 & 0.026 \\
\hline Year 06 & 0.079 & 33.93 & 25.73 & 0.003 & 0.013 & 4.68 & 12.45 & 0.648 \\
\hline Year 07 & 0.061 & 31.00 & 25.73 & 0.009 & 0.024 & 8.56 & 12.45 & 0.215 \\
\hline
\end{tabular}

Table 2: The reduced rank test statistic for daily Finnish and Swedish prices. In the table, $\lambda_{i}$ are the eigenvalues from the reduced rank regression, Tr is the trace test statistic, Tr95 is the $95 \%$-quantiles of the trace distribution, and $p$-val is the probability values associated with the null hypothesis of the given rank in the columns. Bold values indicate insignificant results at a $1 \%$ significance level.

mies accounting for monthly variation were all insignificant, and therefore excluded.

With these choices, we tested the model for long-run structural stability. ${ }^{11}$ There were some indications of a structural shift in the middle of year 2003. For this reason, we consider both the full sample (2001-2007), and the latter half of the sample (2004-2007). In addition, we consider each year separately as a robustness check. ${ }^{12}$

\subsubsection{Cointegration tests on Finnish and Swedish prices}

Table 2 reports the rank test statistic for the different samples. Since we are worried about errors of type I, we choose to conduct the test at the $1 \%$ significance level. Table 2 reveals that $r=0$ is rejected in all samples (although, in year 2007 we are close to non-rejection). Moreover, apart from the relatively stable years 2001 and 2003, we cannot reject the null hypothesis of $r=1$. These results suggest that there is one common stochastic trend in

\footnotetext{
${ }^{11}$ The tests of structural include constancy tests for the coefficient estimates of the identified cointegration space, constancy of the log-likelihood, and constancy of the canonical correlations $\lambda_{i}$, among others. These tests are described in Hansen and Johansen (1999).

${ }^{12}$ It should be noted that a year is in general a very short period within which to investigate the long-run properties of time series, i.e. integration and cointegration. Thus, results may differ to some extent from year to year.
} 


\begin{tabular}{lccccc}
\hline \multicolumn{4}{c}{ Tests of stationarity, weak exogeneity, and trend exclusion } \\
\hline \hline & \multicolumn{4}{c}{$p_{t}^{F I N}$} & \multicolumn{3}{c}{$p_{t}^{S W E}$} & $t$-excl \\
Sample & Stat & Exo & Stat & Exo & \\
Full sample, 01-07 & 0.000 & 0.000 & 0.000 & $\mathbf{0 . 6 9 3}$ & $\mathbf{0 . 1 5 6}$ \\
Half sample, 04-07 & 0.000 & 0.000 & 0.000 & $\mathbf{0 . 2 1 2}$ & $\mathbf{0 . 8 3 4}$ \\
Year 01 & $0.000^{*)}$ & $0.049^{*)}$ & $\left.0.000^{*}\right)$ & $\mathbf{0 . 1 9 7 ^ { * } )}$ & $\mathbf{0 . 9 4 5}$ \\
Year 02 & 0.000 & $\mathbf{0 . 2 7 8}$ & 0.000 & $\mathbf{0 . 1 3 6}$ & $\mathbf{0 . 5 8 9}$ \\
Year 03 & $\mathbf{0 . 0 9 2 * )}$ & $0.000^{*)}$ & $0.036^{*)}$ & $0.007^{*)}$ & $\mathbf{0 . 3 1 0}$ \\
Year 04 & 0.000 & 0.005 & 0.000 & $\mathbf{0 . 6 1 3}$ & $\mathbf{0 . 0 9 7}$ \\
Year 05 & 0.000 & 0.000 & 0.000 & $\mathbf{0 . 6 2 6}$ & 0.025 \\
Year 06 & 0.000 & 0.003 & 0.000 & $\mathbf{0 . 7 2 3}$ & 0.012 \\
Year 07 & 0.000 & $\mathbf{0 . 0 7 1}$ & 0.000 & $\mathbf{0 . 4 3 0}$ & $\mathbf{0 . 9 9 1}$ \\
\hline
\end{tabular}

Table 3: Test of stationarity and weak exogeneity of daily Finnish and Swedish prices given $r=1{ }^{*}$ ) indicates that $r=1$ was rejected in Table 2 . The null hypotheses are that of stationarity and weak exogeneity respectively. The table also reports the null of trend exclusion $(t$-excl). The numbers are p-values of the null hypotheses. Not significant results at the $5 \%$ significance level in bold.

the data and that at least one of the price series is non-stationary. Moreover, if both prices are found to be non-stationary, these must be cointegrated as well.

Table 3 reports the results from testing stationarity and weak exogeneity. The table also reports the results from testing whether the linear trend in the cointegration space can be excluded. As can be seen from Table 3, stationary is rejected in both prices in the full and the half sample. This result implies that Swedish and Finnish prices are cointegrated. Moreover, weak exogeneity cannot be rejected in Swedish prices. Also, the linear trend can be excluded indicating that there are no differences in the deterministic component. The yearly results follow the same structure, with minor differences due to the approximate stationarity in 2001 and 2003, and the near non-rejection of $r=0$ in 2007.

\subsubsection{Test of price homogeneity}

The previous sub-section established that Swedish and Finnish prices are cointegrated. However, as discussed in Section 2, a more strict definition of geographic market delineation for homogeneous goods also requires price homogeneity, or at least approximate price homogeneity, in addition to cointegration. Table 4 reports unrestricted estimates of the cointegration vectors (with the linear trend excluded) and tests of price homogeneity. The table 


\begin{tabular}{llcc}
\hline \multicolumn{3}{c}{ Unrestricted estimates and test of price homogeneity } \\
\hline \hline Sample & Unrestricted estimates & \multicolumn{2}{c}{ test of $p^{F I N}$} \\
Full sample, 01-07 & $p_{t}^{F I N}-\underset{(-102.35)}{0.97} \cdot P^{S W E}$ & $\chi^{2}(1)=7.26$ & 0.007 \\
Half sample, 04-07 & $p_{t}^{F I N}-\underset{(-75.17)}{0.99} \cdot P^{S W E}$ & $\chi^{2}(1)=0.14$ & $\mathbf{0 . 7 0 6}$ \\
Year 01*) & $p_{t}^{F I N}-\underset{(-137.65)}{0.97} \cdot P^{S W E}$ & $\chi^{2}(1)=7.21$ & 0.007 \\
Year 02 & $p_{t}^{F I N}-\underset{(-45.64)}{0.90} \cdot P^{S W E}$ & $\chi^{2}(1)=12.84$ & 0.000 \\
Year 03*) & $p_{t}^{F I N}-\underset{(-15.77)}{0.74} \cdot P^{S W E}$ & $\chi^{2}(1)=8.99$ & 0.003 \\
Year 04 & $p_{t}^{F I N}-\underset{(-23.75)}{0.89} \cdot P^{S W E}$ & $\chi^{2}(1)=4.10$ & 0.043 \\
Year 05 & $p_{t}^{F I N}-\underset{(-17.07}{1.09)} \cdot P^{S W E}$ & $\chi^{2}(1)=0.73$ & $\mathbf{0 . 3 9 1}$ \\
Year 06 & $p_{t}^{F I N}-\underset{(-24.99)}{0.96} \cdot P^{S W E}$ & $\chi^{2}(1)=0.90$ & $\mathbf{0 . 3 4 2}$ \\
Year 07 & $p_{t}^{F I N}-\underset{(-76.65)}{0.95} \cdot P^{S W E}$ & $\chi^{2}(1)=9.39$ & 0.002 \\
\hline
\end{tabular}

Table 4: Unrestricted estimates of the cointegration vector between Finnish and Swedish prices in each sample (the linear trend is excluded), given $r=1{ }^{*}$ ) indicates that $r=1$ was rejected in Table 2. The numbers in parenthesis are t-values. The last two columns test homogeneity between the prices. Bold values indicate non-rejection at the $5 \%$ significance level.

reveals that there is a tendency for Swedish prices to be somewhat higher than the Finnish prices. Furthermore, we note that price homogeneity cannot be rejected in the half sample (2004-2007) and that the prices are never far from homogeneity in any of the other samples.

\subsubsection{Conclusions}

Our econometric test, conducted in line with the procedure summarized in Figure 1, justify the following conclusions.

1. Finnish and Swedish prices are integrated (of the first order).

2. Finnish and Swedish prices are cointegrated and nearly homogeneous.

3. The deterministic linear trend in the price difference is insignificant.

Consequently, our econometric test supports the view that Finland and Sweden constitute the same relevant market for production and wholesale of 
electricity. Furthermore, Swedish prices are (long-run) weakly exogenous indicating that in a structural sense the Swedish price area acts as a price leader relative to the Finnish area. The Swedish prices tend to be somewhat more volatile (in the long run) than the Finnish prices.

\subsubsection{Robustness}

We conducted the reduced rank test statistic on weekly (365 observations) and monthly aggregates (84 observations). We consistently found that $r=0$ was rejected, whereas $r=1$ could not be rejected. Moreover, we found that Swedish prices where weakly exogenous in the lower frequencies as well. Overall, these results are consistent with the results associated with the daily frequency.

We also obtained some results of interest for the hourly frequency. The rank test statistic was not computationally available for a well-specified model of the hourly data (including sufficient lags and dummies for symmetric outliers etc.). However, auxiliary information such as the roots of the companion matrix and the t-values of the $\alpha$-matrix support $r=1$ in the hourly sample as well. Conditional on this choice of rank $(r=1)$, we again found that Swedish prices were weakly exogenous with respect to Finnish prices. In addition, we calculated the half-lives implied by the estimated speed of the equilibrium adjustment of Finnish prices (first $\alpha$ coefficient). These indicated that an average equilibrium shock to the price difference dissipates in slightly less than four hours. Overall, the results associated with hourly data are consistent with the conclusions reported for daily data.

\subsection{Is the Relevant Market More Extensive than Fin- land and Sweden?}

So far our analysis has been restricted to Finland and Sweden. However, Nord Pool defines an integrated market design for a significantly larger area comprising price areas Norway 1, Norway 2, Norway 3, Denmark 1 and Denmark 2, in addition to Finland and Sweden. We now extend our analysis to whole Nord Pool area.

On the Nord Pool level we report the results from the full sample (20012007) and the latter half sample (2004-2007). We do not report individual years, but emphasize that the yearly samples follow similar patterns. In addition, we also report the results from the full sample excluding the year 2007 (i.e. the sample 2001-2006). The reason is that the hydro reservoir level in Norway 1 was close to the maximum level during 2007, thereby inducing an extremely high supply of electricity generated by hydro power in 


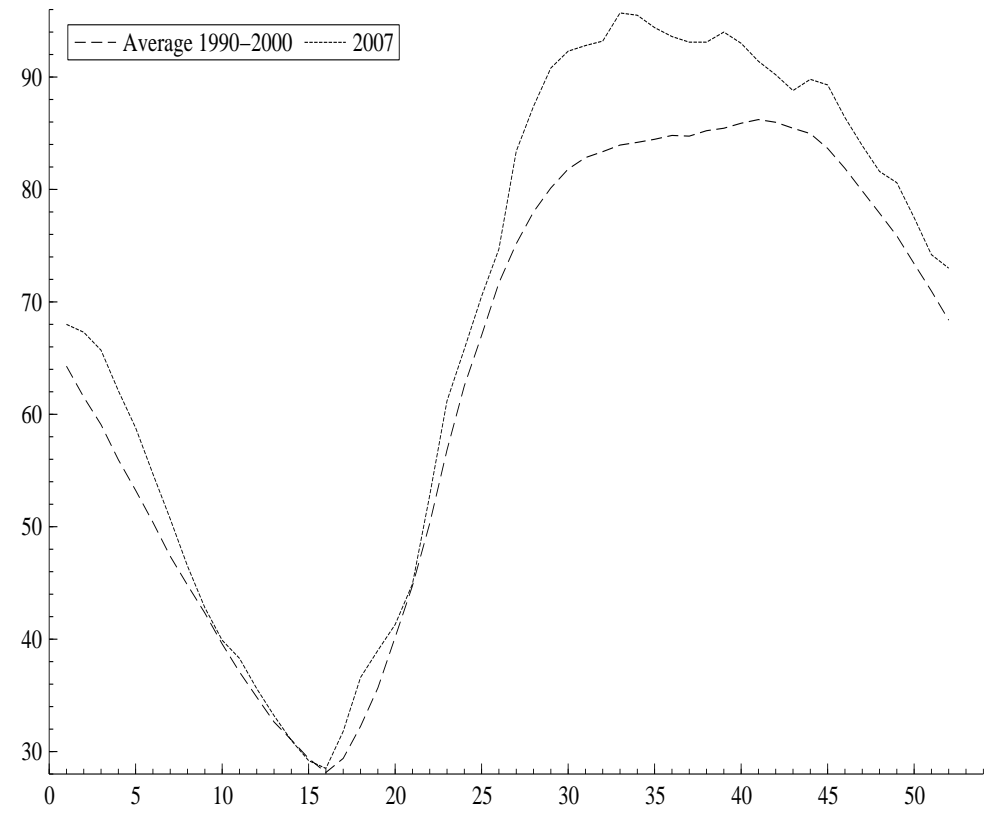

Figure 6: Norway 1 (South Norway) hydro reservoir content (\% of full) in year 2007 compared with a historical average (1990-2000).

order to avoid wastes (see Figure 6). This production exceeded the export transmission capacity of Norway 1, thereby leading, by necessity, to substantially lower prices in Norway 1 compared to the other Nord Pool areas, in particular during the latter half of 2007 (see Figure 7). It turns out that the price deviation in 2007 was sufficiently large and persistent to induce a characterization of Norway 1 as a separate relevant market whenever 2007 is in the sample, as is discussed below. Thus, by excluding 2007 from the full sample we can assess the effect of this particular year on the overall results. As before, we label the logarithms of the prices in the different areas as $p_{t}^{F I N}$, $p_{t}^{S W E}, p_{t}^{N O R 1}, p_{t}^{N O R 3}, p_{t}^{D K 1}$ and $p_{t}^{D K 2}$ respectively.

On the Nord Pool level the prices were modeled by (2), where a trend was included in the cointegration space and identical seasonal dummies were added as before. In a similar fashion as before, 33 dummy variables were added to account for extreme exogenous events that affected at least two or more areas symmetrically. As earlier, at least four lags were needed to account for the variation in the data. Following our procedure for the analysis of Finland and Sweden we selected the lag structure with $k=7$. 

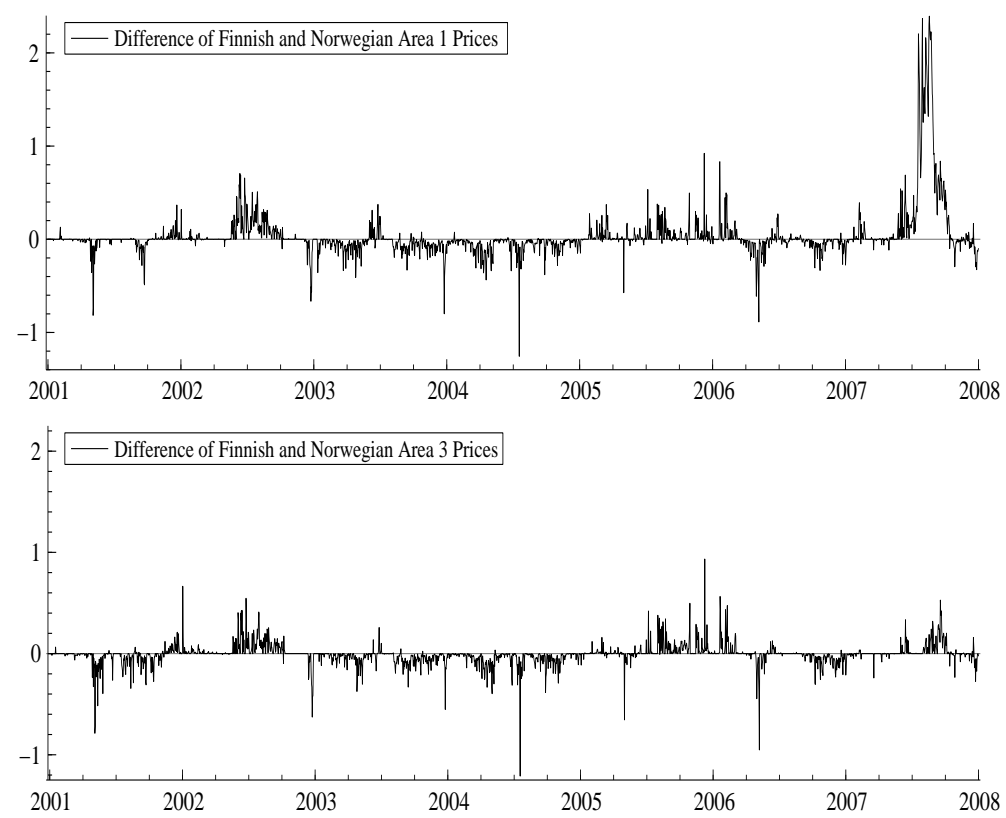

Figure 7: The homogeneous price difference between Finland and Norway area 1 (upper graph), and between Finland and Norway area 3 (lower graph).

\subsubsection{Cointegration tests on Nord Pool prices}

The reduced rank hypothesis is reported in Table 5 . Table 5 indicates that the rank in the full sample is five, independently of whether 2007 is excluded or not. This implies that all non-stationary Nord Pool prices are cointegrated, because they share the same stochastic trend. Hence, the non-stationary area-specific prices cannot evolve independently of each other. In other words these price areas impose competitive discipline on each other. The table also shows that the rank is four in the half sample. Given that the area-specific

\begin{tabular}{ccccccc}
\hline \multicolumn{6}{c}{ Reduced rank hypothesis, $X_{t}=\left(p_{t}^{F I N}, p_{t}^{S W E}, p_{t}^{N O R 1}, p_{t}^{N O R 1}, p_{t}^{D K 1}, p_{t}^{D K 1}\right)^{\prime}$} \\
\hline \hline & $r=0$ & $r=1$ & $r=2$ & $r=3$ & $r=4$ & $r=5$ \\
Full sample, 01-07 & 0.000 & 0.000 & 0.000 & 0.000 & 0.003 & $\mathbf{0 . 4 7}$ \\
Half sample, 04-07 & 0.000 & 0.000 & 0.000 & 0.000 & $\mathbf{0 . 1 8 7}$ & $\mathbf{0 . 7 3 4}$ \\
Full sample, 01-06 & 0.000 & 0.000 & 0.000 & 0.000 & 0.000 & $\mathbf{0 . 6 8 2}$ \\
\hline
\end{tabular}

Table 5: The reduced rank test statistic for Nord Pool prices. The numbers are $p$-values of the null hypothesis of the ranks given in the columns. Not significant results at the $1 \%$ significance level in bold. 


\begin{tabular}{lcccccccc}
\hline \multicolumn{7}{c}{ Tests of stationarity } & and weak exogeneity \\
\hline \hline Sample & $r$ & Test & $p_{t}^{F I N}$ & $p_{t}^{S W E}$ & $p_{t}^{N O R 1}$ & $p_{t}^{N O R 3}$ & $p_{t}^{D K 1}$ & $p_{t}^{D K 2}$ \\
Full sample, 01-07 & 5 & Stat & 0.000 & 0.000 & 0.000 & 0.000 & 0.000 & 0.000 \\
& & Exo & 0.000 & 0.000 & 0.004 & $\mathbf{0 . 5 3 2}$ & 0.000 & 0.000 \\
Half sample, 04-07 & 4 & Stat & 0.000 & 0.000 & 0.000 & 0.000 & 0.000 & 0.000 \\
& & Exo & 0.000 & 0.000 & $\mathbf{0 . 1 9 7}$ & $\mathbf{0 . 3 1 6}$ & 0.000 & 0.000 \\
Full sample, 01-06 & 5 & Stat & 0.000 & 0.000 & 0.000 & 0.000 & 0.000 & 0.000 \\
& & Exo & 0.000 & 0.000 & $\mathbf{0 . 1 1 2}$ & 0.014 & 0.000 & 0.000 \\
\hline
\end{tabular}

Table 6: Test of stationarity and weak exogeneity of daily Nord Pool prices given $r=1$. The null hypotheses are that of stationarity and weak exogeneity respectively and the numbers are p-values of the null hypotheses. Not significant results at the $5 \%$ significance level in bold.

prices are non-stationary, the case with a rank $r=4$ would facilitate an interpretation according to which Nord Pool can be decomposed into at least two separate relevant markets. We demonstrate below that the additional unit-root originates in the extreme conditions in Norway 1 during 2007.

Table 6 reports the results of testing stationarity and weak exogeneity on all area-specific prices in the samples. Table 6 shows that stationarity can be rejected for all area-specific prices, regardless of sample (the time horizon) or choice of rank. Thus, for the full samples 2001-2007 and 2001-2006 the prices in all Nord Pool areas are cointegrated. Furthermore, in the half sample the Nord Pool area prices can potentially be divided into three groups according to whether they exclusively share one of the two stochastic trends or whether they contain both trends. Interestingly, $p_{t}^{N O R 3}$ is weakly exogenous in the full sample when 2007 is included, whereas $p_{t}^{N O R 1}$ is weakly exogenous when 2007 is excluded. Both $p_{t}^{N O R 1}$ and $p_{t}^{N O R 3}$ are weakly exogenous is the half sample. These results suggest that Norway 1 acts as the price leader under normal conditions, like those prevailing when year 2007 is excluded. However, during the abnormal year 2007, when the export transmission capacity of Norway 1 was exceeded, the role of price leader was taken over by Norway 3 . Under all circumstances, the two Norwegian areas serve as price leaders relative to all other price areas in Nord Pool. Moreover, exclusion of the restricted linear trend could not be rejected regardless of the sample or the choice of rank.

\subsubsection{Tests of price homogeneity}

The system approach adopted in this paper allows for simultaneous tests of price homogeneity between two or more Nord Pool price areas. It seems natural to begin by conducting pairwise tests and subsequently to extend 


\begin{tabular}{lcccc}
\hline \multicolumn{4}{c}{ Stochastic trends and their loadings } \\
\hline \hline & Full sample, 01-07 & \multicolumn{1}{c}{ Half Sample, 04-07 } & Full sample, 01-06 \\
& $r=5$ & \multicolumn{2}{c}{$r=4$} & $r=5$ \\
& $\sum_{i=1}^{t} \varepsilon_{i}^{N O R 3}$ & $\sum_{i=1}^{t} \varepsilon_{i}^{N O R 3}$ & $\sum_{i=1}^{t} \varepsilon_{i}^{N O R 1}$ & $\sum_{i=1}^{t} \varepsilon_{i}^{N O R 1}$ \\
$p_{t}^{F I N}$ & 0.523 & 0.469 & 0.020 & 0.381 \\
$p_{t}^{S W E}$ & $(4.250)$ & $(6.568)$ & $(0.793)$ & $(4.969)$ \\
$p_{t}^{N O 1}$ & 0.544 & 0.485 & 0.010 & 0.403 \\
$p_{t}^{N O 3}$ & $(4.250)$ & $(6.709)$ & $(0.388)$ & $(4.969)$ \\
$p_{t}^{D K 1}$ & 0.729 & -0.182 & 0.768 & 0.436 \\
$p_{t}^{D K 2}$ & $(4.250)$ & $(-1.243)$ & $(14.530)$ & $04.969)$ \\
& 0.566 & 0.489 & 0.028 & $(4.969)$ \\
& $(4.250)$ & $(6.487)$ & $(1.027)$ & 0.191 \\
& 0.335 & 0.221 & 0.116 & $(4.969)$ \\
& $(4.250)$ & $(4.288)$ & $(6.239)$ & 0.355 \\
\end{tabular}

Table 7: Loadings to the stochastic trends in the Norwegian prices. The numbers in parenthesis are $t$-values.

the tests by successively adding more areas. Much effort can be saved by investigating the loadings of the common stochastic trends (see equation (5)) prior to formally testing price homogeneity, since price pairs that are very far from homogeneity are easily detected that way.

Given the weak exogeneity results we know that the common stochastic trends, $\alpha_{\perp}^{\prime} \sum_{i=1}^{t} \varepsilon_{i}$, consist of the two Norwegian prices. Labeling these as $\sum_{i=1}^{t} \varepsilon_{i}^{N O R 1}$ and $\sum_{i=1}^{t} \varepsilon_{i}^{N O R 3}$ respectively, Table 7 reports the loadings to each trend. Table 7 reveals that, in the full sample 2001-2007, prices in the Nord Pool areas Finland, Sweden, Norway 3 and Denmark 2 have similar loadings. For instance the relative loading between Finland and Sweden is $c_{F I N} / c_{S W E}=0.523 / 0.544=0.96$ (see Section 2). Denmark 2 and Norway 3 have the smallest relative loading, $c_{D K 2} / c_{N O 3}=0.85$, which is rather far from unity. Norway 1 and Denmark 1 each have significantly different loadings from the rest. Based on these observations, we only report the tests of price homogeneity within the subset $\left\{p_{t}^{F I N}, p_{t}^{S W E}, p_{t}^{N O 3}, p_{t}^{D K 2}\right\}{ }^{13}$ The upper part of Table 8 reports pairwise tests of price homogeneity. As can be seen from the table, none of the pairwise tests were rejected, although some price pairs came close to rejection. The lower part of Table 8 reports the test of price homogeneity between three or more prices within the subset $\left\{p_{t}^{F I N}, p_{t}^{S W E}, p_{t}^{N O 3}, p_{t}^{D K 2}\right\}$. The only non-rejections occur for the subsets $\left\{p_{t}^{F I N}, p_{t}^{N O 3}, p_{t}^{D K 2}\right\}$ and $\left\{p_{t}^{S W E}, p_{t}^{N O 3}, p_{t}^{D K 2}\right\}$. However, the other subsets of

\footnotetext{
${ }^{13}$ The homogeneity tests for other price pairs or groups were rejected. The detailed results are available upon request.
} 
Tests of price homogeneity in the sample 2001-2007

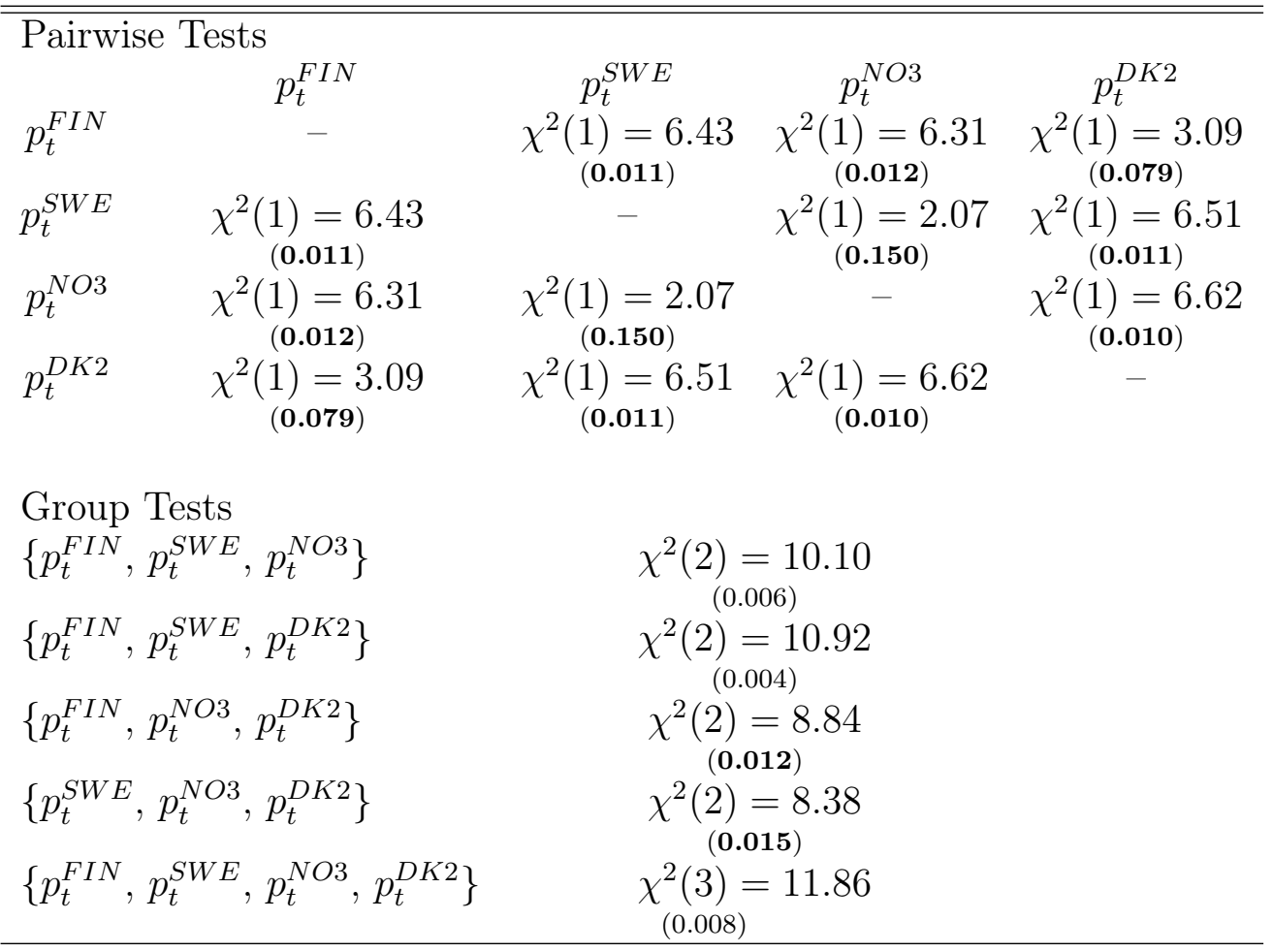

Table 8: Tests of price homogeneity between Finland, Sweden, Norway 3 and Denmark 2 for the sample 2001-2007. The upper part of the table reports pairwise tests, whereas the lower part reports tests between larger groups of price series. The test statistic is distributed as $\chi^{2}(d f)$ and $p$-values are reported in parenthesis below the test statistic. Bold numbers indicate non-rejection of price homogeneity at the $1 \%$ significance level in the respective price areas. 


\begin{tabular}{|c|c|c|c|}
\hline \multicolumn{4}{|c|}{ Tests of price homogeneity in the sample $2001-2006$} \\
\hline$\left\{p_{t}^{F I N}, p_{t}^{S W E}, p_{t}^{N O 1}\right\}$ & $\begin{array}{c}\chi^{2}(2)=15.78 \\
(0.000)\end{array}$ & $\left\{p_{t}^{S W E}, p_{t}^{N O 3}, p_{t}^{D K 2}\right\}$ & $\chi^{2}(\underset{\mathbf{0 . 0 3 3})}{2}=6.86$ \\
\hline$\left\{p_{t}^{F I N}, p_{t}^{S W E}, p_{t}^{N O 3}\right\}$ & $\begin{array}{c}\chi^{2}(2)=7.31 \\
(\mathbf{0 . 0 2 6})\end{array}$ & $\left\{p_{t}^{N O 1}, p_{t}^{N O 3}, p_{t}^{D K 2}\right\}$ & $\begin{array}{c}\chi^{2}(2)=19.90 \\
(0.000)\end{array}$ \\
\hline$\left\{p_{t}^{F I N}, p_{t}^{S W E}, p_{t}^{D K 2}\right\}$ & $\begin{array}{c}\chi^{2}(2)=8.87 \\
(\mathbf{0 . 0 1 2})\end{array}$ & $\left\{p_{t}^{F I N}, p_{t}^{S W E}, p_{t}^{N O 1}, p_{t}^{N O 3}\right\}$ & $\begin{array}{c}\chi^{2}(3)=19.19 \\
(0.000)\end{array}$ \\
\hline$\left\{p_{t}^{F I N}, p_{t}^{N O 1}, p_{t}^{N O 3}\right\}$ & $\chi^{2}(2)=18.19$ & $\left\{p_{t}^{F I N}, p_{t}^{S W E}, p_{t}^{N O 1}, p_{t}^{D K 2}\right\}$ & $\begin{array}{c}\chi^{2}(3)=16.61 \\
(0.001)\end{array}$ \\
\hline$\left\{p_{t}^{F I N}, p_{t}^{N O 1}, p_{t}^{D K 2}\right\}$ & $\begin{array}{c}\chi^{2}(2)=16.57 \\
(0.000)\end{array}$ & $\left\{p_{t}^{F I N}, p_{t}^{S W E}, p_{t}^{N O 3}, p_{t}^{D K 2}\right\}$ & $\begin{array}{c}\chi_{(\mathbf{0 . 0 2 9})}^{2}(3)=9.03 \\
\end{array}$ \\
\hline$\left\{p_{t}^{F I N}, p_{t}^{N O 3}, p_{t}^{D K 2}\right\}$ & $\chi_{(\mathbf{0 . 0 3 1})}^{2(2)=6.98}$ & $\left\{p_{t}^{F I N}, p_{t}^{N O 1}, p_{t}^{N O 3}, p_{t}^{D K 2}\right\}$ & $\begin{array}{c}\chi^{2}(3)=20.05 \\
(0.000)\end{array}$ \\
\hline$\left\{p_{t}^{S W E}, p_{t}^{N O 1}, p_{t}^{N O 3}\right\}$ & $\chi_{(0.001)}^{2}(2)=14.79$ & $\left\{p_{t}^{S W E}, p_{t}^{N O 1}, p_{t}^{N O 3}, p_{t}^{D K 2}\right\}$ & $\begin{array}{c}\chi^{2}(3)=20.32 \\
(0.000)\end{array}$ \\
\hline$\left\{p_{t}^{S W E}, p_{t}^{N O 1}, p_{t}^{D K 2}\right\}$ & $\begin{array}{c}\chi^{2}(2)=14.87 \\
(0.001)\end{array}$ & $\left\{p_{t}^{F I N}, p_{t}^{S W E}, p_{t}^{N O 1}, p_{t}^{N O 3}, p_{t}^{D K 2}\right\}$ & $\begin{array}{c}\chi^{2}(4)=21.34 \\
(0.000)\end{array}$ \\
\hline
\end{tabular}

Table 9: Tests of price homogeneity between Finland, Sweden, Norway 1, Norway 3 and Denmark 2 for the sample 2001-2006. The test statistic is distributed as $\chi^{2}(d f)$ and $p$-values are reported in parenthesis below the test statistic. Bold numbers indicate nonrejection of price homogeneity at the $1 \%$ significance level in the respective price areas.

prices were rejected by a very narrow margin at the $1 \%$ level of significance. Overall, we view this evidence as supportive of price homogeneity between Finland, Sweden, Norway 3 and Denmark 2 in the full sample, 2001-2007.

For the half sample 2004-2007 the table reveals that Finland, Sweden and Norway 3 share the same stochastic trend with similar loadings. Denmark 2 shares the same stochastic trend with these areas, but with significantly different loading. The price in Norway 1 develops according to a separate stochastic trend, whereas Denmark 1 shares both these stochastic trends. These results suggest that Finland, Sweden, and Norway 3 possibly belong to the same relevant market. The joint test of price homogeneity between the prices in these areas generate $\chi^{2}(2)=7.37$ and a $p$-value of 0.025 , i.e. a non-rejection of price homogeneity at the $1 \%$ significance level. Thus, we can draw the conclusion that Finland, Sweden and Norway 3 belong to the same relevant market in the half sample. ${ }^{14}$

Finally, Table 7 reveals that the price in Denmark 1 has a significantly different loading from other prices in the sample covering 2001-2006. Table 9 reports the results from testing price homogeneity in all groups of three or more Nord Pool prices from the set $\left\{p_{t}^{F I N}, p_{t}^{S W E}, p_{t}^{N O 1}, p_{t}^{N O 3}, p_{t}^{D K 2}\right\}$. Inter-

\footnotetext{
${ }^{14}$ Pairwise test between these prices support this conclusion. Price homogeneity was rejected for all combinations between $p_{t}^{D K 1}$ or $p_{t}^{N O 1}$ and other prices. These results are available upon request.
} 
estingly, Table 9 reveals that price homogeneity cannot be rejected in any such group which excludes the price in Norway 1 . On the other hand, price homogeneity is always rejected in all groups containing the price in Norway 1. Thus, we have reasons to draw the conclusion that Nord Pool price areas Finland, Sweden, Norway 3 and Denmark 2 belong to the same relevant market in the sample 2001-2006.

In light of data there seems to be a strong relationship between Nord Pool system prices and deviations of the Nordic (mostly Norwegian) hydro reservoir levels compared with the norm of the year. More precisely, strong reductions in the deviation of the reservoir level relative to norm seem to have driven the visible incidents of price increases since 2001. Due to restrictions in transmission capacity between price areas, this price effect is stronger in areas with a higher proportion of hydro generated power. ${ }^{15}$ This pattern is clearly visible in Table 7 , where the relative loadings to the stochastic trends are highest for the Norwegian areas, followed successively by Sweden, Finland, and Denmark. This also seems to explain the instances and patterns of deviations from complete price homogeneity. Interestingly, these results bear resemblance to the result obtained by Walls (1994) for the U.S. natural gas industry.

\subsubsection{Conclusions}

Our econometric test on the whole Nord Pool level, conducted in line with the procedure in Section 4.2, justify the following conclusions. ${ }^{16}$

1. All area-specific prices are non-stationary.

2. The area-specific prices are cointegrated with cointegration rank 5 in the samples 2001-2007 and 2001-2006, whereas is cointegration rank is 4 in the sample 2004-2007.

3. During time horizons 2001-2007, as well as 2001-2006, the prices in the Nord Pool areas Finland, Sweden, Norway 3, and Denmark 2 share the same stochastic trends with the same loadings. We draw the unambiguous conclusion that the Nord Pool areas Finland, Sweden Norway 3, and Denmark 2 belong to the same relevant market during these periods.

\footnotetext{
${ }^{15}$ Hydro power constitutes $98 \%$ of the electricity capacity in Norway, $48 \%$ in Sweden, $18 \%$ in Finland, and 0\% in Denmark at the end of 2006 (see Nordel annual report and Nord Pool).

${ }^{16}$ As before, we conducted sensitivity analysis with respect to the reduced rank test statistic on weekly and monthly frequencies. The results where similar to those obtained on the daily frequency.
} 
4. Areas Norway 1 and Denmark 1 define separate markets on their own during the periods 2001-2007 and 2001-2006.

5. During the time horizon 2004-2007 the prices areas Finland, Sweden, and Norway 3 belong to the same relevant market. Areas Norway 1, Denmark 1, and Denmark 2 define separate markets on their own.

6. There is a clear tendency that the price areas rich in hydro power serve as price leaders relative to other areas in the same relevant market. Restrictions in international transmission capacity tend to generate higher price volatility in these areas relative to the other areas. During normal hydro power conditions (the period 2001-2006), the stochastic trend in prices originates in price area Norway 1 . However, if we include the year 2007 this role is taken over by price area Norway 3 .

Figure 8 depicts the decomposition of Nord Pool price areas into different relevant markets consistent with the econometric evidence. The figure also illustrates the structure of the common stochastic trends in each sample. This market decomposition is reported for the different time horizons 20012007, 2004-2007 or 2001-2006. The figure shows that Finland, Sweden, and Norway 3, unambiguously belong to the same relevant market regardless of the time horizon. Denmark 2 belongs to this same market in the samples 2001-2007 and 2001-2006, but defines its own market in the sample 20042007. Norway 1 and Denmark 1 always define their own separate markets.

\section{Bottlenecks in the Transmission Capacity be- tween Finland and Sweden}

We now return to a detailed investigation of bottlenecks in the transmission capacity between Finland and Sweden. During a small proportion of hours with price differences the international transmission capacity has been insufficient to induce price equalization between Finland and Sweden. Figure 5 presents a graphical representation of the frequency by which such price differences are realized. We refer to such states of nature simply as bottlenecks. Table 10 presents a descriptive yearly account of the number and proportion of hours when there has been a bottleneck in the international transmission capacity between Finland and Sweden. We can observe that during the period 2001-2007 there has been a price difference between Finland and Sweden during $11,47 \%$ of the hours. When there has been a bottleneck in the 


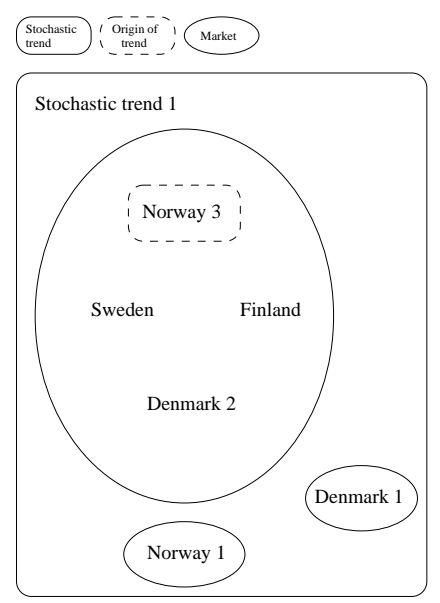

(a) Market delineation, 2001-07.
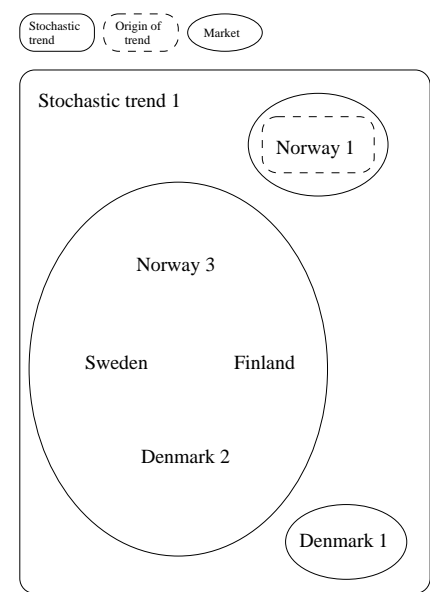

(b) Market delineation, 2001-06

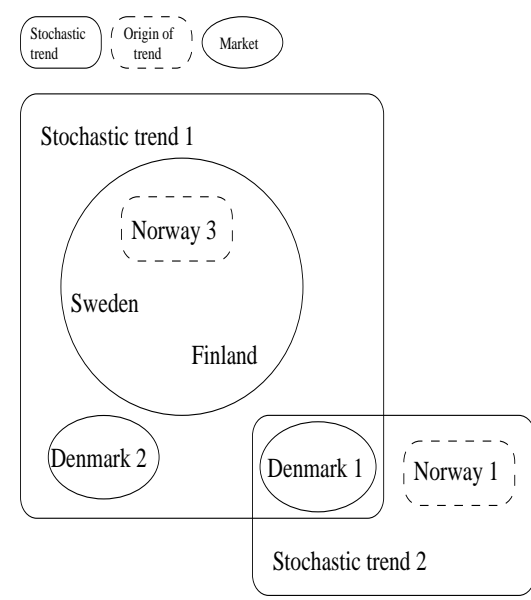

(c) Market delineation, 2004-07

Figure 8: Nord Pool market delineation and structure of the common stochastic trends based on the results from different samples. 


\begin{tabular}{ccccccccc}
\hline & \multicolumn{7}{c}{ Bottleneck Statistics (hours) } \\
\hline \hline$\#\left\{P_{t}^{F I N}>P_{t}^{S W E}\right\}$ & 2001 & 2002 & 2003 & 2004 & 2005 & 2006 & 2007 & $2001-2007$ \\
$\#\left\{P_{t}^{F I N}<P_{t}^{S W E}\right\}$ & 66 & 262 & 0 & 0 & 739 & 227 & 44 & 1301 \\
$\#\left\{P_{t}^{F I N} \neq P_{t}^{S W E}\right\}$ & 96 & 439 & 2561 & 2092 & 77 & 375 & 385 & 5733 \\
$\#\left\{P_{t}^{F I N}=P_{t}^{S W E}\right\}$ & 8663 & 8320 & 6198 & 6691 & 7943 & 8157 & 8330 & 54302 \\
$T$ & 8759 & 8759 & 8759 & 8783 & 8759 & 8759 & 8759 & 61337 \\
$\#\left\{P_{t}^{F I N}>P_{t}^{S W E}\right\}$ & $0.34 \%$ & $2.99 \%$ & $0.00 \%$ & $0.00 \%$ & $8.44 \%$ & $2.59 \%$ & $0.50 \%$ & $2.12 \%$ \\
$\#\left\{P_{t}^{F I N}<P_{t}^{S W E}\right\}$ & $0.75 \%$ & $2.02 \%$ & $29.24 \%$ & $23.82 \%$ & $0.88 \%$ & $4.28 \%$ & $4.40 \%$ & $9.35 \%$ \\
$\#\left\{P_{t}^{F I N} \neq P_{t}^{S W E}\right\}$ & $1.09 \%$ & $5.01 \%$ & $29.24 \%$ & $23.82 \%$ & $9.32 \%$ & $6.87 \%$ & $4.90 \%$ & $11.47 \%$ \\
$\#\left\{P_{t}^{F I N}=P_{t}^{S W E}\right\}$ & $98.91 \%$ & $94.99 \%$ & $70.76 \%$ & $76.18 \%$ & $90.68 \%$ & $93.13 \%$ & $95.10 \%$ & $88.53 \%$ \\
\hline$T$
\end{tabular}

Table 10: Bottleneck statistics between Finland and Sweden. $\#\{\cdot\}$ denotes the number of the set and $T$ is the total sample size.

transmission capacity between Finland and Sweden the price difference has predominantly, during $9,35 \%$ of the hours, been to the advantage of buyers in the Finnish market.

With a definition of the relevant market as national it would, from a theoretical point of view, be logically inconsistent to refer to structural competition problems during phases of bottlenecks in the transmission of electricity between Finland and Sweden. The presence of bottlenecks in the transmission of electricity between Finland and Sweden is an issue, which is, in principle, unrelated to whether the Finnish market performs well as a national market given the constraints imposed by the Finnish production technology. Bottlenecks in the transmission of electricity between Finland and Sweden constrain the ability to efficiently exploit the joint supply in the two countries, but this does not imply any type of abuse of market power or any other types of strategically induced distortions in the Finnish national market. Such bottlenecks just mean that consumers are restricted to the national sources available for electricity generation, and these might not always be able to match the efficiency of the sources available in the other country. By logical necessity arguments identifying the bottlenecks of electricity transmission between Finland and Sweden as the core of potential structural competition problems imply that the underlying relevant market is larger than the Finnish national market and incorporate at least Finland and Sweden. This inconsistency could potentially be reconciled by introducing an intertemporal separation of the relevant market into two phases: the phase when there is no congestion for the transmission of electricity between Finland and Sweden and the phase when there is congestion of intercon- 
nections between these countries. ${ }^{17}$ In most markets such an intertemporal separation could not easily be conducted, but the remarkable transparency of the Nord Pool market for electricity with prices determined regularly and with high frequency, i.e. every hour, might at least theoretically make such an intertemporal separation possible. Apparently, the idea behind such an intertemporal separation could then be that the behavior of a potentially dominant firm in Finland would not be constrained by the competitive dynamics of the Swedish market during those hours when there is congestion of interconnections.

When evaluating the existing bottleneck statistics the crucial question is the following: Has the incidence of the fairly infrequent bottlenecks had any significant price effects? In light of the cointegration analysis conducted in the previous section we can conclude that the incidence of infrequent bottlenecks has induced no such persistent price effects so as to justify a view of Finland and Sweden as defining separate relevant markets. On the contrary, the cointegration analysis generated evidence in strong support of Finland and Sweden belonging to the same relevant market even though our econometric model was designed so as to create a bias in favor of the inference supporting separate relevant markets.

Based on hourly area-specific prices one can draw some further descriptive conclusions regarding the nature of the bottlenecks. The duration of bottlenecks has predominantly been very short, typically one hour or at most a few consecutive hours. There is no significant relationship between the hour of the day or the weekday and the incidence of a bottleneck. Furthermore, there is no evidence that the bottlenecks would occur more frequently during the winter months with the yearly regular peak in demand. As a matter of fact, if the winter period is defined as December-March the average frequency of bottlenecks is $0,7 \%$ (9,9\%) during the winter months 2001-2005 in association with those bottlenecks when the Finnish (Swedish) price exceeds the Swedish (Finnish) price. ${ }^{18}$ Thus, available data does not support the view with bottlenecks emerging as a demand-driven phenomenon. Instead the variations in hydro inflow and the complexity associated with the intertemporal reservoir management together with other stochastic disturbances in the power generation seem to be the primary explanations for the emergence of bottlenecks. Overall, in light of the detailed bottleneck statistics it does not seem credible that the states with bottlenecks emerge in a way which is predictable to the

\footnotetext{
${ }^{17}$ As pointed out in our introduction, such an intertemporal separation has been suggested by the Finnish Competition Authority.

${ }^{18}$ This should be compared with the yearly frequency of of bottlenecks reported in Table 10. The average frequency of bottlenecks with the Finnish (Swedish) price exceeding the Swedish (Finnish) price during 2001-2005 was 2,3\% (11,3\%).
} 
market participants. Furthermore, these states are typically not of such a duration so as to have antitrust implications.

An intertemporal separation in the definition of the relevant market would have far-reaching consequences for the implementation of competition law and for competition policy more generally. The same argument in support of an intertemporal separation of the definition of the relevant market could then be applied in all markets characterized by the combination of demand fluctuations and capacity constraints. Such a policy would easily give incentives for firms to establish excess capacity so as to avoid the risk of being accused of abusing a dominant position in a phase where a bottleneck is realized, i.e. a phase where demand exceeds the available capacity. For that reason such a competition policy would induce distortions with excess capacity and thereby not promote efficient investments. In this respect such an intertemporal separation of the electricity market into an hour-by-hour market would most likely counteract the overall goal of competition policy as a structural microeconomic policy tool with the objective of promoting efficiency in the long run.

\section{Concluding Comments}

In this study we applied cointegration analysis to daily aggregates of hourly price observations during the period 2001-2007 in the Nord Pool price areas with the objective of empirically characterizing the geographical dimension of the relevant market for production and wholesale of electricity in the Nordic countries. We initially established econometrically that Finland and Sweden belong to the same relevant market by demonstrating that Finnish and Swedish area prices are cointegrated and homogeneous. We subsequently extended our analysis to the whole Nord Pool area and were able to establish econometrically that the price areas Finland, Sweden and Norway 3 unambiguously belong to the same relevant market. Furthermore, we found that the price area Denmark 2 belongs to this same market when evaluated over the periods 2001-2007 or 2001-2006, but defines its own market over the period 2004-2007. Norway 1 and Denmark 1 define separate relevant markets on their own for each of the time periods studied. We also found a clear tendency that the price areas rich in hydro power serve as price leaders relative to other areas in the same relevant market. During normal hydro power conditions (the period 2001-2006), the stochastic trend in prices originates in price area Norway 1. However, if we include the year 2007 this role is taken over by price area Norway 3 .

We presented detailed hourly statistics of bottlenecks in the international 
transmission capacity between Finland and Sweden in order to evaluate the competition policy option of an intertemporal separation in the definition of the relevant market into two phases depending on whether restrictions in the international transmission capacity prevents the operation of competition. We argued that such an intertemporal separation of the electricity market into an hour-by-hour market would most likely counteract the overall goal of competition policy as a structural microeconomic policy tool with the objective of promoting efficiency in the long run. And, under all circumstances in light of the econometric evidence such an intertemporal separation of the relevant markets is not consistent with the persistency requirements imposed by the SSNIP-test.

The frequency for the emergence of bottlenecks in the transmission of electricity between countries is largely determined by the capacity of interconnections between these countries. A proper structural assessment of the relevant market should not be restricted to past and present market performance, but it should also take the likely and foreseeable future development of the relevant industry into account. In particular, the significance of the problem with bottlenecks should also be evaluated in light of existing commitments and plans for future capacity expansions of the interconnections between countries.

The transmission system operators in the Nordic countries (Denmark, Finland, Iceland, Norway and Sweden) manage and coordinate the investments into capacity of transmission of electricity between the Nordic countries within the framework of NORDEL. The export capacity from Sweden to other Nordic countries is in total 8010 MW, out of which 2230 MW towards Finland. Similarly, the interconnection capacity from Finland to other Nordic countries is $1930 \mathrm{MW}$, out of which $1830 \mathrm{MW}$ is an export connection to Sweden. The total export and import capacities for Sweden are fairly equal, 9210 MW and 9470 MW, respectively. For Finland the total existing capacity for import, $4240 \mathrm{MW}$, substantially exceeds the capacity for export, $2280 \mathrm{MW}$. Furthermore, total Nordic capacity for imports from other countries (Russia, Estonia, Poland and Germany) is $4710 \mathrm{MW}$, whereas the interconnection capacity for Nordic electricity export to the same non-Nordic countries is 3550 MW. In light of these capacities together with planned investments to further improve the interconnections between national markets we can conclude that effort is made in order to control the incidence of bottlenecks. Borenstein et al. (2000) present an interesting and relevant theoretical analysis, designed primarily with the Californian market in mind, of the transmission capacity necessary for two local markets to achieve the benefits of competition within the framework of an integrated market. It is also an overall goal of European energy policy to promote an expansion of international interconnections in 
order to support a development in a direction towards the development with the ultimate goal of creating a European market for production and wholesale of electricity. Of course, the likely transformation towards a unified European market for production and wholesale of electricity will successively enlarge the relevant market towards a European level.

Discussions of international interconnection capacity are easily biased towards a view according to which higher interconnection capacity always generates benefits. However, it should be kept in mind that it is not socially optimal to establish such an extensive interconnection capacity that the probability for the emergence of a bottleneck would be reduced to zero. As always, the socially optimal capacity is determined by the condition that the expected marginal social benefit of an additional incremental unit of capacity is equal to its marginal social cost. Our characterization of the relevant markets within the framework of Nord Pool identifies those price areas for which an extended transmission capacity might have particularly high benefits. From an overall Nordic perspective high export transmission capacities from Norway seem particularly valuable in light of our study.

\section{References}

Bohn Nielsen, H., 2004. Cointegration analysis in the presence of outliers. Econometrics Journal 7, 249-271.

Borenstein, S., Bushnell, J., Stoft, S., 2000. The competitive effects of transmission capacity in a deregulated electricity industry. The RAND Journal of Economics 31, 294-325.

Forni, M., 2004. Using Stationarity Tests in Antitrust Market Definition. American Law and Economics Review 6, 441-464.

Franses, P., Haldrup, N., 1994. The Effects of Additive Outliers on Tests for Unit Roots and Cointegration. Journal of Business \& Economic Statistics $12(4), 471-478$.

Hansen, H., Johansen, S., 1999. Some tests for parameter constancy in cointegrated VAR-models. Econometrics Journal 2 (2), 306-333.

Horowitz, I., 1981. Market Definition in Antitrust Analysis: A RegressionBased Analysis. Southern Economic Journal 48, 1-16.

Johansen, S., 1991. Estimation and Hypothesis Testing of Cointegration Vectors in Gaussian Vector Autoregressive Models. Econometrica 59, 15511580 . 
Johansen, S., 1995. Likelihood-Based Inference in Cointegrated Vector AutoRegressive Models. Oxford University Press.

Marcellino, M., 1999. Some Consequences of Temporal Aggregation in Empirical Analysis. Journal of Business \& Economic Statistics 17 (1), 129-136.

Otero, J., Smith, J., 2000. Testing for cointegration: power versus frequency of observation - further Monte Carlo results. Economics Letters 67, 5-9.

Slade, M., 1986. Exogeneity Tests of Market Boundaries Applied to Petroleum Products. The Journal of Industrial Economics 34, 291-303.

Spiller, P., Huang, C., 1986. On the Extent of the Market: Wholesale Gasoline in the Northeastern United States. The Journal of Industrial Economics $35,131-145$.

Stigler, G., Sherwin, R., 1985. The Extent of the Market. Journal of Law and Economics 28, 555-585.

Uri, N., Rifkin, E., 1985. Geographic Markets, Causality and Railroad Deregulation. The Review of Economics and Statistics 67, 422-428.

Vandezande, L., Meeus, L., Delvaux, B., Van Calster, G., Belmans, R., 2006. Evaluation of Economic Merger Control Techniques Applied to the European Electricity Sector. The Electricity Journal 19, 49-56.

Walls, D., 1994. A Cointegration Rank Test of Market Linkages with an Application to the U.S. Natural Gas Industry. Review of Industrial Organization 9, 181-191. 